\title{
51 Prevalência de enxaqueca entre universitários e seus familiares
}

\author{
Hellen Maria Santos da Silva (iD, Nathalia Herculano de Sousa (D), Luana de Oliveira Leite ${ }^{(D)}$, \\ Ana Patrícia Pascoal Queiroz de Araújo (iD, Maria da Glória Canto de Sousa ${ }^{D}$, \\ Alcylene Carla de Jesus dos Santos $\mathbb{D}^{\mathrm{D}}$, Acássia Benjamim Leal Pires
}

Universidade do Estado da Bahia, Salvador, Bahia, Brasil.

\section{Introdução}

A genética da enxaqueca sem aura e a enxaqueca com aura está sendo estudada com auxílio de grandes estudos de associação de genomas. Entretanto, é necessário a caracterização da base genética de populações específicas.

\section{Objetivo}

Verificar se universitários com enxaqueca possuem susceptibilidade genética para esse distúrbio.

\section{Material e Métodos}

Estudo descritivo de corte transversal realizado entre estudantes universitários de uma universidade pública da Bahia no período de dezembro de 2020 a junho de 2021. Os questionários foram aplicados mediante convocação por redes sociais e aplicativos de mídia e preparados na plataforma FORMS (Google LLCR, Califórnia, EUA). Inicialmente eram direcionados para o Termo de Consentimento Livre e Esclarecido (TCLE) e somente após poderiam responder às questões. Essa pesquisa foi aprovada pelo Comitê de Ética e Pesquisa da Universidade do Estado da Bahia (UNEB) CAAE:38038720.5.0000.0057 - Parecer 4.351.53.

\section{Resultados}

Um total de 83 universitários que responderam ao questionário, 85,5\% afirmaram sofrer de enxaqueca. A média de idade foi de 25 anos (+/- 6,9) e 81,9\% eram do sexo feminino. A maioria (>80\%) afirmou ser de naturalidade baiana, sendo que $41 \%$ se autodeclararam de cor preta e 31,3\% parda. Dos estudantes que informaram a presença de enxaqueca, 54,2\% informaram ter histórico familiar de enxaqueca, sendo que a mãe foi mais citada para 33,7\% deles, seguidos por tios $(18,1 \%)$, irmãos $(13,3 \%)$, pais $(10,8 \%)$ e avós $(4,8 \%)$.

\section{Conclusões}

Em jovens universitários da Bahia com enxaqueca, o histórico familiar foi presente em mais de 50\%, indicando que a enxaqueca tem um importante componente genético neste grupo. Além disso, esse levantamento mostra a necessidade de caracterizar melhor os fatores genéticos influenciadores na ocorrência de enxaqueca nesses estudantes a fim de possibilitar estratégias terapêuticas mais efetivas, uso adequado de medicamentos e prevenção da cronificação desse tipo de cefaleia.

Palavras-chave: Genética; Migrânea 